\section{"À MORTE COM O SINDICATO": CONFLITO E EMERGÊNCIA DE UMA GREVE DE JOGADORES DE FUTEBOL NA ESPANHA (2011)}

\author{
"DYING WITH THE UNION": CONFLICTS AND EMERGENCE OF A FOOTBALL \\ PLAYERS' STRIKE IN SPAIN (2011)
}
"LA MUERTE CON EL SINDICATO": CONFLICTOS Y EMERGENCIA DE LA HUELGA DE JUGADORES DE FÚTBOL EN ESPAÑA (2011)

Mariana Zuaneti Martins*, Heloisa Helena Baldy dos Reis**

\begin{abstract}
Palavras chave: Sindicatos.

Futebol.

Atletas.

Greve.

Resumo: Este artigo objetivou descrever e analisar a greve dos jogadores espanhóis de futebol, em 2011, iniciada a partir das orientações sindicais manifestadas em processo anterior e durante o movimento. É fruto de pesquisa documental nos jornais espanhóis El País e Marca, de 2008 a 2013, e notícias do sindicato de jogadores da Espanha. Os documentos foram cotejados a fim da reconstituição da narrativa e análise à luz da ideia de Hyman, da geometria sindical. É mostrado que, após mudança na gestão do sindicato, tentativas foram feitas de mobilização, que gradativamente foram alterando as orientações do sindicato em direção a uma ideologia mais classista, pautada na solidariedade e unidade, mas também integração societal, que possibilitaram a emergência da greve.
\end{abstract}

Keywords: Labor unions.

Soccer.

Athletes.

Employee's strike.

Palabras clave: Sindicatos.

Fútbol.

Atletas

Huelga de empleados.

Abstract: This article describes and analyzes Spain's 2011 football players' strike under their union's orientation - before and during the strike. In order to accomplish this, we conducted documental research on two Spanish newspapers (EI País and Marca, from 2008 to 2013) and information provided by the football players' Union. We verified those sources to reconstruct the narrative and analyze it based on Hyman's views on union geometry. Our results suggest that after a change in the union's leadership, attempts at mobilization pointed to a classist ideology based on the concept of solidarity and unity, as well as society integration. The strike emerged in that scenario.

Resumen: Este artículo tiene como objetivo describir y analizar la huelga de futbolistas españoles del año 2011, de las orientaciones sindicales que se pudieron de manifiesto en el proceso previo y durante el conflicto. Este es el resultado de la investigación documental en el diario español El País y el Marca, 2008-2013, así como la información recabada de la Asociación de Futbolistas Españoles. Los documentos han sido cotejados con el fin de la reconstrucción de la narración y posterior análisis, a la luz de la idea de Hyman de la geometría sindical. Se demuestra que, después de un cambio en la gestión del sindicato, se hicieron intentos de movilización, que fueron cambiando gradualmente las orientaciones del sindicato hacia una ideología más clasista, basada en la solidaridad y la unidad, además de la integración social, lo que hizo posible el nacimiento de la huelga.
*Universidade Federal do Espírito Santo. Vitória, ES, Brasil.

E-mail: fale.com.marief@gmail.com

**Universidade Estadual de Campinas. Campinas, SP, Brasil. E-mail: heloreis14@gmail.com

Recebido em: 07-03-2017 Aprovado em: 23-04-2018

DOI: http://dx.doi.org/10.22456/1982-8918.71707 (c) (1) (2) Licence 


\section{INTRODUÇÃO}

Este artigo descreve e analisa a greve dos jogadores espanhóis de futebol, em 2011. A fim de entender essa ação coletiva, descreveremos o processo de organização sindical da Asociación de Futbolistas Españoles (AFE) - sindicato dos jogadores de futebol que atuam em todas as divisões da Espanha -, que culminou na convocação da greve e nas reivindicações por ela apontadas.

O tema da agência ${ }^{1}$ tem sido pouco abordado nos estudos contemporâneos sobre futebol, em especial quando se tratada questão da ação sindical. A predominância da temática do paternalismo nesses estudos tem conduzido a visão sobre o jogador como um elo fraco e, em virtude de alguns mecanismos estruturais, mantido sob a tutela do clube - por meio do passe, até 0 início dos anos 2000, e posteriormente pelo agente²(ARAÚJO, 1980; FLORENZANO, 2009). A consequência é que, ao trabalharem com essa concepção de paternalismo, tais estudos transmitem a concepção de uma classe de profissionais meramente manipulados, sem vontade própria, ou seja, anulam ou reduzem a agência do jogador.

O caso da greve dos jogadores na Espanha, em 2011, no entanto, é um dos momentos em que esses profissionais demonstraram possuir uma agência política. No referido contexto, o conflito de interesses entre clubes e jogadores se explicitou e se desdobrou em uma ação coletiva sindical ${ }^{3}$. Existem especificidades notadas no contexto espanhol: a existência de algumas greves ao longo das décadas de 1970 e $1980^{4}$ e a existência de mecanismos de convênios coletivos por categorias ocupacionais 5 . Além dessas, há outras especificidades que merecem ser aqui apresentadas, para a compreensão da conjuntura pesquisada.

O contexto trabalhista do futebol espanhol da primeira década dos anos 2000 foi marcado por atrasos nos pagamentos e inadimplências salariais que atingiram boa parte dos jogadores profissionais de futebol. Por essa razão, houve tentativas pontuais de paralisações em alguns clubes. Apesar dessas ações, até 2011 não havia existido de fato uma ação coletiva generalizada entre os jogadores que alcançasse toda a categoria ou mesmo impulsionada pelo sindicato. Apresentamos então a questão norteadora deste artigo: o que possibilitou a emergência de uma greve geral no ano de 2011?

A emergência da greve não necessariamente está relacionada apenas à postura da diretoria sindical, visto que, para que ela seja efetiva, não só é imperativo que tal mobilização

\footnotetext{
1 Por agência entendemos a ação humana em prol de algum objetivo, independentemente do nível de consciência, racionalidade ou liberdade envolvido. Por isso, não é objetivo aqui adentrar o debate sobre a prevalência da agência, enquanto "livre" vontade, sobre a estrutura, como as coerções externas ao indivíduo, ou vice-versa. Buscamos uma abordagem relacional desses aspectos a fim de compreender a forma pela qual as estruturas se inscrevem, ou não, na ação dos sujeitos (JESSOP, 2001).

20 agente é o responsável por intermediar as relações entre o clube e o jogador de futebol em uma transição de emprego. Tal figura, credenciada pela Federação Internacional de Futebol (FIFA), ganhou especial proeminência após o fim do passe, na Europa, a partir de 1995, com o caso Bosman, e no Brasil, a partir de 1998, com a Lei Pelé (RODRIGUES, 2007).

3 De acordo com Hyman (1979), o conflito, fruto do antagonismo de interesses entre trabalhadores e patrões, pode apresentar-se de forma latente, oculta ou explícita.

4 Em 1979, um ano após a fundação da AFE, aconteceu a primeira greve de jogadores de futebol na Espanha. Na ocasião, os atletas não jogaram a 23a rodada da Liga, reivindicando: o fim do "passe", o direito de contribuir como trabalhadores para a seguridade social e o fim do limite de idade para inscrição de atletas na terceira divisão do futebol espanhol. Em 1981, ocorreu a segunda greve, na qual os atletas reivindicavam o pagamento das dívidas salariais que os clubes tinham com eles. Essa greve ocasionou 0 atraso na disputa da primeira rodada do Campeonato Espanhol daquele ano. Em 1984, aconteceu a terceira greve, em virtude de inadimplências salariais dos clubes com os jogadores (LA PRIMERA..., 2011).

$5 \mathrm{Na}$ Espanha existe uma tradição de convênios coletivos, o que ajuda a compreender por que isso se desenvolve também no futebol. Segundo Moraes (1981), a Lei dos Convênios Coletivos, uma das propostas de reforma econômica aprovada na Espanha em 1958, tinha como objetivo que as empresas conquistassem "[...] ascendência sobre os elementos nucleares e decisivos da massa trabalhadora, de modo a encaminhar demandas econômicas absorvíveis e programadas, ou seja, compatíveis com os cálculos econômicos das empresas" (MORAES, 
seja chamada pela diretoria, como é preciso quea base a legitime, pois é isso que garantirá a força da paralisação. Uma paralisação pode também ser extraoficial, isto é, feita sem a convocação explícita da diretoria do sindicato, como aconteceu em alguns clubes espanhóis durante os anos 2000. Segundo Hyman (1979), o conflito sindical é baseado em uma disputa sobre o controle das relações de trabalho, em que o empregador tem poder valendo-se do constrangimento legal e o empregado consegue sua força decorrente da atividade que realiza, mas que só se efetiva quando ela é coletiva.

Um aspecto que influencia os sistemas de adesão e emergência de ações coletivas é a orientação sindical segundo a qual o sindicato dos jogadores de futebol age. Hyman (2001, p. 4) descreve que "[...] a orientação da identidade do sindicato, sua ideologia e estratégias são resultados de uma tensão entre instruções que se endereçam ao mercado, às relações de classe ou ao papel integrativo do trabalho na sociedade". De modo geral, são três modelos: sindicalismo de mercado; assistencialista voltado à integração societal; classista.

Esses três modelos sindicais, como tipos ideais, não aparecem puramente na complexidade social. Na medida em que são concorrentes, estão sempre mobilizados em disputa pelos diferentes agentes que atuam nos sindicatos. Se pensarmos esses modelos como parte de uma figura geométrica dentro da qual a ação sindical se desenvolve, poderíamos caracterizá-la como um triângulo, em que cada um de seus vértices representa uma dessas orientações. A ação sindical ocuparia um dos lados do triângulo, entre um vértice e outro, combinando-se na disputa e no hibridismo entre eles. Isso significa que na ação sindical estariam em confronto e em coexistência os modelos de cada um dos vértices que compõe esse triângulo: da classe e da sociedade; da sociedade e do mercado; e do mercado e da classe. Por isso, a opção neste artigo foi descrever a greve de 2011 analisando a relação entre a ação sindical coletiva de jogadores de futebol, o modelo de sindicalismo adotado e a adesão da categoria à mobilização coletiva.

\section{PERCURSO METODOLÓGICO}

Para analisar a greve de 2011 optamos por reconstruir a sua narrativa - como ferramenta analítica para a interpretação de movimentos sociais em ascensão, cujo desfecho ainda não é um dado acabado -, pois esta permite integrar passado, presente e os acontecimentos subsequentes, objetivando evidenciar ambiguidades e transformações pelas quais esses movimentos passam (POLLETTA, 1998).

Para tanto, fizemos um levantamento de reportagens que tratam da temática em estudo nos periódicos El País e Marca, de 2008 a 2013, período em que algumas greves localizadas emergiram no país. A razão pela qual faremos a incursão no período anterior ao das greves se dá pelo fato de que, quando nos direcionamos à compreensão de processos históricos, em especial aqueles que denotam uma transformação, o olhar ao período imediatamente anterior possibilita evidenciar como a mudança transcorreu, o que se alterou e o que se confirmou (ELIAS, 1994) ${ }^{6}$.

Sendo assim, buscamos nas reportagens a repercussão pública dessas movimentações, contendo elementos de distintas opiniões e pontos de vista sobre o movimento. A escolha

6 Ao nos basearmos em documentos da mídia esportiva, decidimos tratá-los na perspectiva do documento-monumento (LE GOFF, 2003), buscando distintas fontes para a reconstituição dessas narrativas da greve, a fim de colocá-las em confronto, demonstrando as diferentes visões sobre os acontecimentos em análise. 
de fontes que congregassem as diferentes repercussões sobre a greve contribuiu para que explicitássemos as ideias recorrentes e as opiniões conflitantes sobre o movimento. Além disso, a fim de complementá-las e cotejá-las com o posicionamento oficial do sindicato, buscamos também notas sobre a greve presentes no sítio da entidade e no Libro de memória da AFE, de 2012 (ASSOCIACIÓN..., 2012) 7 . Assim, remontamos aos acontecimentos da greve, bem como selecionamos depoimentos de jogadores, dos representantes da AFE e dos clubes atuantes no processo de greve, enfocando em excertos que explicitassem a pluralidade de posições que se estabeleceram no processo - recortes estes que compuseram o corpus desta pesquisa.

Alicerçadas nos elementos da narrativa, realizamos a análise das orientações sindicais da greve com base no debate bibliográfico de ação sindical, compreendendo quais são os condicionantes para o desenvolvimento de uma greve, a saber: a relação com a base (HYMAN, 1979), as concepções sobre greve e da natureza do conflito gerado e os modelos sindicais propostos pelas diretorias do sindicato (HYMAN, 2001).Os resultados foram organizados em três momentos distintos: a narrativa inicial da greve; as condições da criação de uma solidariedade na categoria de jogadores de futebol após reorientação sindical da AFE; e as consequências da reorientação da AFE para a compreensão do conflito de interesses entre jogadores e constituição de uma ação coletiva generalizada no futebol espanhol.

\section{A EMERGÊNCIA DA GREVE ENTRE JOGADORES}

O surgimento da greve de 2011 está relacionado a dois aspectos: a crise financeira dos clubes de todas as divisões do Campeonato Espanhol, marcada por atrasos e pelo não pagamento de salários aos jogadores, e pelo surgimento de uma nova liderança na entidade sindical, a quem coube o papel de tentar impulsionar uma paralisação em 2010, convocando-a definitivamente em 2011. Para entender o contexto de 2011, devemos nos remeter ao ano de 2008, com a emergência de uma greve no clube Levante Unión Deportiva, de Valência, e 0 surgimento de Luis Manuel Rubiales como liderança no meio futebolístico. Rubiales tornou-se presidente do sindicato espanholem 2010, sendo uma figura importante para a convocação da greve.

Conforme artigo publicado por El País, greves de jogadores espanhóis ocorreram nos anos de 1979, 1981 e 1984, e nos anos 2000 a ocorrência da inadimplência salarial volta a acontecer, o que se apresenta como um paradoxo do futebol espanhol, uma vez que este se encontra centralmente no circuito mundial do futebol, sendo uma das ligas milionárias do esporte, tendo dois entre os principais clubes mundiais. Segundo dados da revista Forbes de 2012, Real Madrid e Barcelona ocupavam a primeira e a terceira colocação como os clubes mais rentáveis do mundo, tendo um valor estimado de suas marcas de US\$3,6 bilhões e US\$3,5 bilhões, respectivamente (OZANIAN, 2016). O futebol espanhol está organizado em quatro divisões de futebol: primeira divisão; segunda divisão; segunda divisão B e terceira divisão. Nas duas primeiras, cujas competições são organizadas pela Liga de Futebol Profissional (LFP), existiam 42 equipes e cerca de mil jogadores, em 2011. Na segunda divisão B, havia 79 equipes; e na terceira divisão eram 360. Essas duas divisões não são consideradas completamente profissionais. Na primeira e na segunda divisão há convênio coletivo e piso salarial. Contudo, são presentes em todas as divisões a inadimplência salarial, que chega a atravessar mais de uma temporada. 
Ao final da temporada de 2010-2011, havia 32 clubes, da primeira e da segunda divisão do campeonato espanhol, que se encontravam inadimplentes com o salário de seus jogadores (ASSOCIACIÓN..., 2012). No início de agosto, a LFP havia aprovado algumas mudanças, como a criação de um novo fundo de garantia ${ }^{8}$, uma mudança na Ley Concursa ${ }^{\beta}$ para as temporadas de 2014-2015, proveniente de renda repassada pelas La Quiniela10. A AFE, contudo, reclamou dessa mudança, por não ter participado das negociações (UNA GARANTíA..., 2011).

Em agosto de 2011, discordando dos valores concedidos pela LFP, reivindicando negociações e que os jogadores fossem ouvidos, a AFE, depois de reuniões com os capitães das equipes, reunindo mais de cem futebolistas, anunciou a greve em uma coletiva de imprensa. Nela estavam presentes jogadores do selecionado espanhol: Casillas, Xabi Alonso, Puyol, Albelda, Fernando Llorente, que também apoiaram publicamente a greve, comprometendo-se a não entrar em campo para jogar.

As reivindicações exigidas pela AFE eram: o pagamento dos quase cinquenta milhões de euros que os clubes tinham de dívida com jogadores; aumento do fundo social - verba que é destinada pela Real Federación Española de Fútbol (RFEF) ao sindicato para cobrir as inadimplências salariais -; queda automática de divisão dos clubes inadimplentes (IRÍBAR, 2011). Com duas rodadas atrasadas, as competições da liga naquele ano tiveram início quando se firmou acordo entre a AFE e a LFP, garantindo que se resolveria o problema dos duzentos jogadores que não haviam recebido pagamento. 0 novo fundo social fixou uma cláusula segundo a qual o jogador que ficasse três meses sem receber seus provimentos seu contrato com o clube, assim como estabeleceu explicitamente que os clubes que fossem rebaixados obrigatoriamente teriam que pagar o salário de seus jogadores.

Durante a greve, algumas equipes tentaram jogar, além de continuarem com treinamentos. Porém, o movimento criou uma unidade dentro da categoria, gerando um sentido comum na reivindicação, o que forjou uma solidariedade. Diferentemente das paralisações pontuais que ocorreram em alguns clubes durante os anos 2000, a greve de 2011 mobilizou toda a liga. Esse fato pode ser compreendido como uma construção de senso de classe ${ }^{11}$ entre seus sujeitos, uma noção que ultrapassa os interesses econômicos imediatos, afinal vários desses jogadores não estavam ameaçados.

\section{SOLIDARIEDADE E VISIBILIDADE: A GREVE ENTRE OS VÉRTICES DA SOCIEDADE- MERCADO E DA SOCIEDADE-CLASSE}

A greve de 2011 foi desencadeada por um conflito entre os futebolistas e a liga. Nos anos 2000, greves e paralisações localizadas em clubes ocorreram na Espanha, motivadas por atrasos salariais. No caso da greve do clube Levante, de 2008, a situação se complicou ao final das competições da liga, em maio, já que os atrasos salariais ocorriam desde dezembro de 2007. Confluía para a situação o fato de o time, já rebaixado - e com menos expectativas de

\footnotetext{
8 Fundo que cobre as dívidas salariais com os jogadores.

9 Essa lei permitia, mediante autorização judicial, reduzir à metade os compromissos com os credores e diminuir o salário dos jogadores, vigorando para o futebol desde 2004.Em geral, ao serem rebaixados e terem a sua entrada de capital bastante reduzida, os clubes ameaçam os jogadores a concordarem com a redução de salário como condição para permanecer atuando no time (TORRES, 2008).

10 Loteria esportiva espanhola.

11 O conceito de classe, na construção teórica de Hyman (1979), não é apenas uma questão estrutural, que distinguiria, grosso modo aqueles que possuem os meios de produção daqueles que vendem a força de trabalho para sobreviver. A concepção de classe é histórica e contextual, relacionada também a uma questão ideológica. Desse modo, ela é produto da ação dos sujeitos e de suas lutas, já que 0 autor concebe como classe trabalhadora aqueles que compreendem a existência de um conflito de interesse entre eles e seus empregadores.
} 
pagar os atrasados -, disputar sua última rodada contra o Real Madrid, que estava sagrando-se campeão naquele ano. Nessa ocasião, as negociações entre os jogadores e o clube Levante ocorriam, porém não avançavam, e por isso o time ameaçou não jogar a partida contra o Real Madrid. Segundo Rubiales, então jogador do Levante, a reação da equipe técnica do Real Madrid não fora compreensiva.

A paralisação dessa partida não se concretizou por conta da mediação exercida por um jogador do Real Madrid, Raúl González, vedete da seleção espanhola e então vice-presidente da $A F E$, que se comprometera a ajudar os jogadores do Levante, mediando as negociações. Contudo, no dia agendado para a negociação, ele esteve presente por pouco tempo, porque precisou apresentar-se na cidade de Madrid para a exibição do título da Liga dos Campeões (TORRES, 2008).

O papel cumprido por Raúl González foi o de driblar a greve do Levante considerando 0 interesse de seu clube de jogar, sem de fato ajudar a resolver a situação dos jogadores. Nesse caso, González apresentou uma orientação sindical modelada para o mercado, ou seja, os interesses corporativos do clube e a harmonia social, desviando-se do conflito antagônico de classe. Segundo essa orientação sindical, há um pêndulo entre "[...] uma prioridade para melhorias no bem-estar social e coesão social e de suas imagens como representantes dos interesses sociais" e as "representações dos interesses da carreira, esta entendida como desvinculada dos interesses políticos mais gerais" (HYMAN, 2001, p. 3). Esse direcionamento da ação sindical, no entanto, fez com que o jogador se posicionasse contra os interesses dos atletas aos quais ele se propôs a representar na gestão da AFE.

Contudo, essa "formação geométrica" (HYMAN, 2001) da ação sindical se alterou na AFE ao longo dos anos subsequentes, com a entrada de Luis Rubiales como presidente. $O$ discurso mais radicalizado de Rubiales, presente desde que liderou a paralisação dos treinamentos no Levante, foi acentuado na disputa da entidade sindical, em 2010, quando o jogador propôs a organização de representantes de todas as equipes. Desde 1988, a AFE era presidida por Gerardo González Movilla, porque, segundo este, não havia uma oposição ou alguém que se candidatasse. No início de 2010 surgiu a candidatura de Rubiales, que conseguiu com que quase mil e quinhentos associados votassem em sua proposta, baseada na criação de um sistema de garantias para o pagamento de salários, atualização dos convênios coletivos, em especial o da segunda divisão $B$ e a regulação da terceira divisão, fazendo com que Movilla desistisse de disputar o cargo de presidente da associação (MARCOS, 2010a).

Do ponto de vista ideológico, a gestão de Rubiales inaugura um discurso relacionado à identidade e à defesa dos interesses de classe desses jogadores.

\footnotetext{
Nas gestões anteriores, havia pessoas boas, mas dava a impressão de que eram decorativas. Só fazia e desfazia uma pessoa. Por isso, queremos ser uma gestão acessível. Nos vestiários que apresentávamos nosso projeto, nos reconheciam como um deles, porque também padecemos de descumprimentos de contratos. Vamos lutar por um sistema de garantias, que evite que tenhamos que ficar apagando incêndios (MARCOS, 2010b).
}

A inadimplência salarial era o fato mais grave naquele período, e diversas equipes realizavam paralisações em virtude de atrasos de pagamento. Consciente de que mesmo assim muitos jogadores tinham medo de se manifestar publicamente contra essa situação, Rubiales propôs colocar o sindicato como ponta de lança desse processo, de modo que não colocasse 
"no fronte de guerra um jogador que por isso sofreria consequências bastante desagradáveis" (MARCOS, 2010b).

Esse discurso começou a romper com as concepções individualistas do período anterior, seguindo em direção a uma ação coletiva que integrasse não somente os jogadores diretamente e momentaneamente afetados. 0 sindicato operaria publicamente esse processo, unificando os jogadores, de modo que os sujeitos que participassem da greve estariam protegidos pela entidade.

Em 2011, ainda, a AFE convocou uma greve para as últimas rodadas da temporada 2010-2011. Todavia, cabe destacar a forma como a greve foi organizada. A convocação foi operada em uma reunião, dia 29 de março de 2011, com oitenta capitães da primeira e da segunda divisão. A proposta aprovada foi: se até 9 de abril de 2011 a LFP não negociasse os pagamentos em atraso, no dia 16 seria iniciada uma greve (LA AFE CONVOCA..., 2010a).

Nossos direitos, garantias e salários não são para ser mendigados, mas exigidos, e a situação atual é a mais difícil dos últimos vinte anos. Estamos certos de que a AFE pode conseguir a unidade e a solidariedade no futebol, com firmeza e generosidade, tentando manter o diálogo. [...] Somos conscientes de que uma greve não é uma medida positiva, mas tampouco é positiva a situação que vivem os futebolistas que ficam mais de um ano sem receber salário. Por essa razão, não há outro remédio senão 0 de forçar 0 que acreditamos ser justo: 0 cumprimento dos acordos firmados desde 0 ano passado (Rubiales, em entrevista para o Marca) (RUBIALES..., 2010).

Essa fala radicalizou a visão do conflito pelo viés da greve, indicando o surgimento de um vértice classista, orientado à solidariedade e à unidade da categoria. Tal fala indica a mudança da identidade sindical, de modo que a geometria se desloca para o lado da classe e da integração social. Essa orientação apresentou-se também em outro episódio, quando a $A F E$ anunciou que não realizaria uma partida de futebol em determinada data de feriado que era proibida pelo convênio coletivo da categoria (ASSOCIACIÓN..., 2010). Embora a tentativa de suspensão da rodada não tenha vingado, configurando a não concretização da greve na temporada 2010-2011, o conflito foi suspenso graças a uma negociação entre o Consejo Superior de Deportes (CSD), a LFP e a AFE, que estabelecia que haveria um real decreto regulando a distribuição da arrecadação das apostas esportivas na La Quiniela, destinando uma parte para o fundo que cobriria as necessidades do futebol profissional.

Após mais uma temporada enfrentando novas inadimplências, a AFEvoltou a convocar uma greve geral, paralisando o início da temporada de 2011-2012. No entanto, agora outros elementos ajudaram a compreender a viabilidade da convocação - entre eles, podemos vislumbrar uma maior adesão da base às propostas do sindicato. Na primeira reunião de convocação de 2010, havia cerca de oitenta sindicalizados, enquanto que em 2011 havia cerca de cem. Outro aspecto além do quantitativo foi a adesão de figuras importantes, como Casillas, goleiro da seleção espanhola, Xabi Alonso, Puyol, Albelda e Fernando Llorente, demonstrando que, diferentemente da convocação anterior, dessa vez até mesmo os jogadores mobilizadores de mais dinheiro durante as rodadas apoiavam a greve, comprometendo-se publicamente a não jogar (LA AFE CONVOCA..., 2011). Esse aspecto demonstra que sem a participação desses jogadores as partidas perdem o potencial de circulação do capital que é mobilizado pela imagem deles ${ }^{12}$.

12 Rubiales, desde o princípio de sua gestão, quis aproximar os jogadores famosos do sindicato. Por isso, Casillas e David Villa fizeram parte 
Por isso, a greve no futebol não é uma questão meramente quantitativa, mas também qualitativa. Apesar de o índice para medir a força de um sindicato ou uma paralisação ser a proporção de trabalhadores da base que aderem às propostas da entidade (HYMAN, 1979), no caso dos jogadores de futebol essa conta é um pouco complexa. Isso porque o impacto que uma greve ocasiona, do ponto de vista do prejuízo, não está diretamente relacionado a uma diminuição na quantidade de trabalho realizado, mas à circulação de capital afetada pelo trabalho não realizado. Dito de outra maneira, talvez uma paralisação que mobilize todos os jogos da segunda divisão a remeta a um prejuízo menor que a paralisação de um clássico da primeira divisão, já que este último impactaria não somente a arrecadação de valores com ingressos, mas também de valores advindos da transmissão televisiva. Desse modo, quando uma pequena parcela de jogadores famosos adere à paralisação, de imediato a greve torna-se mais visível e com um impacto maior ao espetáculo esportivo. Esse elemento pode ser explicado pelas características estruturais do futebol, uma vez que a imagem de jogadores famosos é um elemento que mobiliza a circulação de capital relacionado à modalidade esportiva (KEHL; BUCCI, 2004; KLEIN, 2006).

\section{ENTRE A CLASSE E A SOCIEDADE: CONCEPÇÕES SOBRE GREVE, CONFLITO, UNIDADE E SOLIDARIEDADE}

O processo narrado anteriormente demonstra a reorientação para uma geometria sindical localizada entre os vértices da integração social e do conflito de classe, o que será possível demonstrar com base nas concepções sobre a greve explicitadas por jogadores de futebol. Essa reorientação não é um modelo sindical puro, já que mesmo entre os dirigentes da AFE os discursos variavam da esfera da integração social, na perspectiva de que o conflito deve ser harmonizado, para a ideia de que existe um antagonismo de interesses, e os jogadores iriam reivindicar os deles.

Desde 2008, quando realizou sua primeira paralisação no Levante, Rubiales descrevia uma concepção de greve que explicitava um conflito de classe, destacado pelas críticas à gestão do clube. A fala de Rubiales versava: "[...] nossa intenção não é prejudicar qualquer pessoa. Queremos jogar, mas precisamos de uma solução para parar com a greve. A culpa é da má gestão do clube" (LUIS RUBIALES..., 2008). Contudo, essa concepção apresenta-se paradoxal, uma vez que, ao dizer que os jogadores não queriam prejudicar ninguém, Rubiales ignorava que o fator de força de uma greve é justamente o seu caráter "impeditivo".

Tal assertiva criava uma dicotomia entre a defesa da greve e o direito de realizá-la, quando Rubiales afirmava que a greve é "um direito e não uma medida de pressão" (MARCOS, 2010c). Ao contrapor direito e pressão, o presidente da AFE quer dizer que ele opta por utilizar o primeiro como uma autoridade fundada na legitimidade da dominação racional-legal ${ }^{13}$, que the confere força. No caso da pressão, ela também é baseada em uma grandeza de força, mas que tem como base a coação e não a legitimidade. Desse modo, Rubiales operou uma divisão entre dois elementos que Ihe garantiriam força: a pressão e o direito. Segundo Dagnino (2004), na medida em que a própria noção do que vem a ser um direito é produzida socialmente, a legitimidade que garante sua força é posterior. Anteriormente, deve existir outra forma de força,

dela. Segundo a AFE, isso representava uma "[...] solidariedade com os companheiros de profissão, independentemente da divisão ou clube que eles representem" (FIFPRO, 2010). 
como a coletividade envolvida, que o ajude a ganhar essa legitimidade e produzir socialmente esse direito.

No ato do anúncio da greve em 2011, Rubiales defendeu uma concepção de greve e de conflito que não era baseada no antagonismo de interesses, mas no cumprimento do que havia sido acordado: "[...] é uma situação, é lamentável e não se pode argumentar nada mais aos futebolistas, não tem mais o que lhes pedir. Não queremos mais dinheiro, queremos que nossos contratos sejam cumpridos" (LA AFE CONVOCA..., 2011). Tal assertiva funda-se em uma legitimidade racional-legal, baseada em procedimentos e normas que, independentemente do contexto, devem ser seguidos (WEBER, 1999).

Rubiales também explicitou o conflito retirando dele a ideia de harmonia e de legitimidade universal, enfocando o viés de classe: "[...] são nossos cavalos de batalha; não hesitaremos em seguir adiante para acabar com as injustiças que permitem o sistema [...]. Os jogadores são os que mais geram arrecadação e deveriam participar da divisão dela, já que trabalham e a produzem" (NO DUDAREMOS..., 2010). Se nos excertos anteriores a tônica do discurso de Rubiales apontava para um caráter universalista - um caráter de legitimidade, como são os direitos, que afetaria a todos -, nesse caso ele já se direciona a um conflito que tem lados com interesses antagônicos, os de classe (HYMAN, 1979).

A partir da criação desse conflito, se forjou um sentimento de unidade da categoria, o que a orientou entre um vértice classista e um vértice da integração societal (HYMAN, 2001), uma vez que a defesa dos interesses dos jogadores não tão bem-sucedidos advém da ideia de que os jogadores de futebol possuem uma identidade coletiva enquanto trabalhadores do espetáculo futebolístico. Essa identidade foi radicalizada sobretudo pelos jogadores de equipe menores, como é possível vislumbrar na declaração de apoio irrestrito à entidade: "[...] à morte com o nosso sindicato: sentimo-nos bem representados. Há um enorme problema com o futebol: ele gera dinheiro, mas mesmo assim há futebolistas sem receber, e nós estamos lutando para ter essas garantias mínimas" (LA AFE CONVOCA..., 2011). Do ponto de vista dos jogadores famosos, a fala de Casillas é heurística sobre a questão da solidariedade: "[...] penso que temos que ser solidários com a gente que está passando mal [...]. Rubiales falou por todos nós, e nós estamos apoiando-lhe até 'a morte"' (LA AFE CONVOCA..., 2011).

Quando a greve foi retratada pelo lado dos empregadores, o conflito se explicitou, evidenciando o desejo da liga de manter seus interesses preservados. Desde o princípio, a liga dizia que não tinha necessidade de greve, porque a negociação estava em curso (LA AFE CONVOCA..., 2011). Além disso, José Luis Astiazarán, presidente da liga, declarou que "[...] as exigências do sindicato se endureceram [...] se admitirmos hoje que são 200 futebolistas com atrasos, estamos falando de $20 \%$ do total. Comparado ao desemprego da Espanha, eles pelo menos têm trabalho" (LA HUELGA..., 2011). Se até 2010 o conflito com a liga estava latente, em uma tentativa de colaboração, na greve de 2011 ele tornou-se cada vez mais visível, exposto, evidenciando os polos opostos entre capital e trabalho.

\section{CONSIDERAÇÕES FINAIS}

A reflexão sobre a ação coletiva entre jogadores de futebol pode levantar aspectos importantes sobre as condições que favorecem a organização de uma categoria profissional pouco reconhecida pelo seu caráter sindical. Mais que uma condição contextual, o que tornou 
possível a greve de 2011 foi a confluência da renovação da gestão da AFE e o subsequente deslocamento da orientação sindical da entidade. Sendo assim, a greve foi um processo que envolveu mudanças na organização e na identidade coletiva dos jogadores espanhóis.

No plano da organização coletiva, a mudança foi em relação à união da categoria toda em torno de reivindicações relacionadas a melhores condições para exercício da profissão que transbordavam da perspectiva individual. Essa questão colocou em evidência um conflito com a liga e os clubes, que criticaram a ação da greve e suas demandas, afirmando que tal manifestação era inviável. Dessa forma, o conflito de classe, antes latente, em 2011 tornou-se evidente (HYMAN, 1979), colocando em lados opostos os trabalhadores - os jogadores - e a patronal - a liga.

No plano da identidade coletiva, a greve ajudou a forjar uma solidariedade entre os jogadores espanhóis. Os jogadores de renome internacional, mesmo não sendo atingidos diretamente pelos atrasos salariais, se solidarizaram e construíram a greve. Tal evento demonstrou também como é possível, mesmo com as dificuldades advindas da situação de trabalho da profissão, construir uma identidade coletiva enquanto trabalhadores do espetáculo futebolístico e demarcada pela solidariedade aos interesses gerais da categoria.

\section{REFERÊNCIAS}

LA AFE convoca huelga general. Marca, Madrid, 9 abr. 2010a. Disponível em: $<$ http://www. marca.com/2010/04/09/futbol/1adivision/1270810856.html>. Acesso em: 23 nov. 2013.

ARAÚJO, Ricardo Benzaquen. Os gênios da pelota: um estudo do futebol como profissão. 1980. 90f. Dissertação (Mestrado em Antropologia Social) - Universidade Federal do Rio de Janeiro, Rio de Janeiro, 1980.

ASOCIACIÓN DE FUTBOLISTAS ESPAÑOLES (AFE). Libro dememória: AFE 2012. Madrid, 2012.

ASOCIACIÓN DE FUTBOLISTAS ESPAÑOLES (AFE). Nota de 23 de dezembro de 2010. Madrid, 2010. Disponível em: <www.afe-futbol.com>. Acesso em: 25 nov. 2013.

EL BARÇA se entrena voluntariamente a pesar de La huelga. Marca, Madrid, 20 ago. 2011. Disponível em: <http://www.marca.com/2011/08/20/futbol/equipos/barcelona/1313831552.html>. Acesso em: 23 nov. 2013.

DAGNINO, Evelina. Sociedade civil, participação e cidadania: de que estamos falando. In: MATO, D. (Coord.). Políticas de ciudadanía y sociedad civil em tiempos de globalización. Caracas: FACES; Universidad Central de Venezuela, 2004. p. 95-110.

ELIAS, Norbert. O processo civilizador: uma história dos costumes. Rio de Janeiro: Jorge Zahar, 1994. v. 1.

FÉDÉRATION INTERNATIONALE DES ASSOCIATIONS DE FOOTBALLEURS PROFESSIONNELS (FIFPRO).Casillas and Villa in board Spanish Union AFE. Madrid, 9 Sept. 2010. Disponível em: <http://www.fifpro.org/en/news/casillas-and-villa-in-board-spanish-unionafe>. Acesso em: 25 nov. 2013. 
“À morte com o sindicato": conflito e emergência de uma greve de jogadores de futebol na Espanha (2011)

FLORENZANO, João Paulo. A democracia corinthiana: práticas de liberdade no futebol brasileiro. São Paulo: EDUC, 2009.

UNA GARANTÍA para al lanarel convenio. El País, Madrid, 4 ago. 2011. Disponível em: <http:// elpais.com/diario/2011/08/04/deportes/1312408801 850215.html>. Acesso em: 23 nov. 2013.

LA HUELGA de futbolistas sigue adelante. El País, Madrid, 17 ago. 2011. Disponível em: <http:// deportes.elpais.com/deportes/2011/08/17/actualidad/1313565713 850215.html>. Acesso em: 23 nov. 2013.

HYMAN, Richard. Industrial Relations: a Marxist Introduction. Houndmills: Macmillan,1979.

HYMAN, Richard. Understanding European Trade Unionism: between market, class and society. London: Sage, 2001.

IRÍBAR, Amaya. La huelga cobra fuerza. El País, Madrid, 18 ago. 2011. Disponível em: <http:// elpais.com/diario/2011/08/18/deportes/1313618403_850215.html>.Acesso em: 23 nov. 2013.

JESSOP, Bob. Institutional re(turns) and the strategic-relational approach. Environmentand Planning, v.33, n. 7, p. 1213-1235, Jul. 2001.

LOS JUGADORES del Levante iran a La huelga. El País, Madrid, 20 mayo 2008. Disponível em: $<$ http://deportes.elpais.com/deportes/2008/05/12/actualidad/1210576926 850215.html>. Acesso em: 23 nov. 2013.

KEHL, Maria Rita; BUCCI, Eugenio.Videologias. São Paulo: Boitempo, 2004.

KLEIN, Naomi. Sem logo. 5. ed. Rio de Janeiro: Record, 2006.

LE GOFF, Jacques. História e memória. Tradução de Irene Ferreira, Bernardo Leitão, Suzana Ferreira Borges. 5. ed. Campinas: Editora da UNICAMP, 2003.

LUIS RUBIALES: "Hay compañeros sufriendo embargos, con números rojos y vendiendo el coche". El País, Madrid, 22 abr. 2008. Disponível em: <https://elpais.com/deportes/2008/04/22/ actualidad/1208848928 850215.html>. Acesso em: 23 nov. 2013.

MARCOS, Jose.Rebelion em la AFE. El País, Madrid, 22 feb. 2010a. Disponível em: <http:// elpais.com/diario/2010/02/23/deportes/1266879611_850215.html>. Acesso em: 23 nov. 2013.

MARCOS, Jose Rubiales: "Quiero acabar com los pobres". El País, Madrid, 29 mar. 2010b. Disponível em: <http://elpais.com/diario/2010/03/29/deportes/1269813630 850215.html>. Acesso em: 23 nov. 2013.

MARCOS, Jose. La AFE convoca una huelga para dentro de dos fines de semana. El País, Madrid, 6 abr. 2010c. Disponível em: <http://elpais.com/diario/2010/04/06/ deportes/1270504809 850215.html>. Acesso em: 23 nov. 2013.

MORAES, Reginaldo Carmello Correa. Distensão política e sindicalismo: notas para uma investigação comparativa entre os movimentos sindicais espanhol e brasileiro. Perspectiva, n. 4, p. 23-28, 1981. Disponível em: <http://piwik.seer.fclar.unesp.br/perspectivas/article/ viewFile/1707/1388>. Acesso em: 30 nov. 2013.

NO DUDAREMOS en seguir adelante. El País, Madrid, 13 abr. 2010. Disponível em: <http:// elpais.com/diario/2010/04/13/deportes/1271109607_850215.html>.Acesso em: 23 nov. 2013. 
OZANIAN, Mike. The World's Most Valuable Soccer Teams 2016. Forbes, Nova York, May 11, 2016. Disponível em: <http://www.forbes.com/sites/mikeozanian/2016/05/11/the-worlds-mostvaluable-soccer-teams-2016/\#52e92e732d04>. Acesso em: 18 fev. 2017.

POLLETTA, Francesca. "It was like a fever..." Narrative and identity in social protest. Social Problems, v. 45, n. 2, p. 137-159, May1998.

LA PRIMERA huelga desde 1984. El País,Madrid, 17 nov. 2011. Disponível em: <http://deportes. elpais.com/deportes/2011/08/17/actualidad/1313565715 850215.html>. Acesso em: 23 nov. 2013.

EL RACING es el único que paro los cuatro dias. Marca, Madrid, 23 ago. 2011. Disponível em: $<$ http://www.marca.com/2011/08/23/futbol/equipos/racing/1314086355.html>. Acesso em: 23 nov. 2013.

RODRIGUES, Francisco Xavier Freire. 0 fim do passe e a modernização conservadora no futebol brasileiro (2001-2006). 2007. 345f. Tese (Doutorado em Sociologia) - Universidade Federal do Rio Grande do Sul, Porto Alegre, 2007.

RUBIALES: "Los derechos de los jugadores no deben ser mendigados, sino exigidos". Marca, Madrid, 5 abr. 2010. Disponível em: <http://www.marca.com/2010/04/05/ futbol/1adivision/1270498683.html>. Acesso em: 23 nov. 2013.

TORRES, Diego. Hay que tomar medidas. El País, Madrid, 20 mayo 2008. Disponível em: <http://elpais.com/diario/2008/05/20/deportes/1211234402 850215.html>. Acesso em: 23 nov. 2013.

WEBER, Max. Os tipos de dominação. In:WEBER, M. Economia e sociedade. Brasília, DF: Editora da Universidade de Brasília, 1999. v. 1.

\section{Apoio:}

Fundo de Apoio ao Ensino, à Pesquisa e à Extensão (FAEPEX)- Universidade Estadual de 